\title{
Maternal Mortality, Proteinuria and Pregnancy Induced Hypertension: Case Study of a Regional Hospital in Brong Ahafo Region, Ghana
}

\author{
Article by Jacob Kwadwo Amponsah Abebrese ${ }^{1}$, Samuel Fosu Gyasi ${ }^{2}$, Vincent NimoAfriyie ${ }^{3}$, \\ Isaac Kwofie $^{3}$ and Ephraim Kobina ${ }^{3}$ \\ ${ }^{1}$ Office of the Medical Directorate, Brong Ahafo Regional Hospital, Sunyani \\ ${ }^{2}$ Dept. of Energy \& Environmental Engineering, University of Energy and Natural Resources, \\ Sunyani

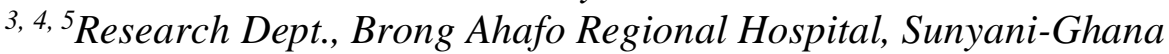 \\ E-mail: abebresejacob@gmail.com ${ }^{1}$
}

\begin{abstract}
Globally, one of the public health problems confronting the medical community is maternal mortality. This study seeks to investigate the relationship between maternal mortality, proteinuria and pregnancy induced hypertension among some pregnant mothers in Ghana. In this study, protein in the urine and blood pressure of some 450 pregnant women who visited the Hospital between Januarys to December, 2015 were monitored. Retrospective data based on maternal death from January 2010 and December 2015 were also retrieved and analysed. This was augmented by interviewing150 respondents (75 each from antenatal and postnatal section of the hospital) based on maternal health history, knowledge on PIH etc. The results of the study with respect to proteinuria and the blood pressure (BP) monitoring showed that, $36 \%$ of these mothers had traces of protein in their urine whiles 32 mothers out of 450 had elevated systolic and diastolic BP. The study also revealed, when data on maternal mortality and PIH of pregnant mothers were retrieved that, a total of 75, $439(N=75,439)$ mothers attended the antennal section of the Hospital. Out of this, 139 of them (0.18\%) died due to PIH. Maternal child bearing behaviour, nulliparity when analysed showed that, greater proportions of antenal (AN) mothers (32.00\%) were nulliparous compared to their PN counterpart $(0 \%)$ ( $p<0.0001)$. Results of our study has shown that, maternal mortality due to PIH were high due to elevated systolic and diastolic blood pressure as well as high doses of trace amount of protein in pregnant mothers' urine.
\end{abstract}

Keywords: Maternal, Mortality, Eclampsia, Clinical, Hypertension, Postnatal.

\section{Introduction}

Globally, one of public health problems confronting the medical community especially in the developing world is maternal mortality (WHO, 2007). This is underlined by the continuing occurrence of more than half a million deaths of women annually due to pregnancy-related complications globally, $99 \%$ of which are distributed in developing countries (WHO, 2005). Maternal mortality (MM) appears to be particularly common in sub-Sahara Africa and South Asia. Improving maternal health is 1 of the 8 Millennium Development Goals (MDGs) adopted by the International community in 2000 (WHO, 2007). In sub-Saharan Africa, a number of countries have halved their levels of maternal mortality since 1990 (Abeberese et al., 2015). In other regions, including Asia and North Africa, even greater headway has been made. However, between 1990 and 2013, the global maternal mortality ratio (i.e. the number of maternal deaths per 100000 live births) has declined by only $2.6 \%$ per year. This is far from the annual decline of 5.5\% required to achieve MDG5 (Takahiro et al., 2011). It is an undeniable fact that one of the leading cause of maternal mortality documented in Africa is pregnancy induced hypertension (PIH) leading to eclampsia.

Eclampsia is the development of convulsions and/or unexplained coma during pregnancy or postpartum in mothers after delivery. In the western world, reported incidence of PIH leading to 
DOI: $10.21522 / \mathrm{TIJPH} .2013 .05 .04$. Art015

ISSN: $2520-3134$

eclampsia ranges from 1 in 2,000 to 1 in 3,448 pregnancies (Thasneem et al., 2014). The reported incidence is usually higher in tertiary referral centers, multifetal gestation and populations with no prenatal care. The main predisposing cause of eclamptic convulsions continues to be the subject of extensive investigation and speculation. Several theories and etiologic mechanisms have been implicated as possible factors, but none of these have been conclusively proven (Bahar, 2005). This has led to the conclusion that, some of the etiologic mechanisms that are implicated in the pathogenesis of eclamptic convulsions include cerebral vasoconstriction or vasospasm hypertensive encephalopathy, cerebral edema or infarction, cerebral hemorrhage as well as metabolic encephalopathy. However, it is not clear whether these findings are causes or an effects of the convulsions (Stevenet al., 2010).

The diagnosis of eclampsia is secured in the presence of generalized edema, hypertension, proteinuria and convulsions. However, women in whom eclampsia develops exhibit a wide spectrum of signs, ranging from severe hypertension, severe proteinuria and generalized edema to absent or minimal hypertension, no proteinuria and no edema (Chames et al., 2001). Thus PIH is considered the hallmark for the diagnosis of eclampsia. The PIH can be severe (at least $160 \mathrm{~mm} \mathrm{Hg}$ systolic and/or at least $110 \mathrm{~mm}$ $\mathrm{Hg}$ diastolic) in 20-54\% of cases (Mammaro et al., 2009) or mild (systolic blood pressure between 140 and $160 \mathrm{~mm} \mathrm{Hg}$ or diastolic blood pressure between 90 and $110 \mathrm{~mm} \mathrm{Hg}$ ) in 30-60\% of cases (Sharma et al., 2013).However, in $16 \%$ of the cases, PIH may be absent. In addition, severe hypertension is more common in patients who develop antepartum eclampsia (58\%) and in those who develop eclampsia at 32 weeks of gestation or earlier (71\%). Moreover, PIH is absent in only $10 \%$ of women who develop eclampsia at or before 32 weeks of gestation (Sibai, 2005). The diagnosis of eclampsia is usually associated with proteinuria (at least 1on dipstick). In a series of 399 women with eclampsia studied by (Pannu et al., 2014), substantial proteinuria (3on dipstick) was present in only $48 \%$ of the cases, whereas proteinuria was absent in $14 \%$ of the cases. Abnormal weight gain (with or without clinical edema) in excess of 2 pounds per week during the third trimester might be the first sign before the onset of eclampsia, but edema was absent in $26 \%$ of 399 eclamptic women studied by the author(Pannu et al., 2014). Several clinical symptoms are potentially helpful in establishing the diagnosis of eclampsia. These symptoms may occur before or after the onset of convulsions, and they include persistent occipital or frontal headaches, blurred vision, photophobia, epigastric and/or right upper-quadrant pain, and altered mental status. Patients will have at least one of these symptoms in $59-75 \%$ of the patients, whereas visual changes are reported in 19-32\% of the patients (Uzan et al., 2011). The BA Regional Hospital (Formally Sunyani Regional Hospital) was established on 11th May 1927 by the then Colonial Masters as a Hospital for the people of Western Ashanti. Since the establishment of the hospital the population of Sunyani and Brong Ahafo had increased more than 10 fold (Annon. 1, 2016). The hospital with a vision of becoming a World Class Healthcare Organization of repute and in "Best Practice" in the Medical and Nursing Care and in the Training high caliber Medical by year 2010.

In recent times, there has been growing concerns among the public and some media landscape about the quality of health care delivery in this Regional Hospital which they believe has led to high mortality rate. The questions that require quick answers is that, is behavioural trends and dietary habits leading to elevated blood pressure and high doses of protein in urine causing pre eclampsia resulting in maternal death at the BA Regional Hospital? In spite of these concerns, there is no empirical data upon which these accessions are underpinned or could be verified. This present study seeks to investigate the relationship between maternal mortality, proteinuria and PIH among AN mothers in BA Regional Hospital, Ghana.

\section{Methods}

Study area: The study was conducted in the Brong Ahafo (BA) Regional Hospital in Sunyani. Sunyani municipality is one of the districts in this region as shown in Figure 1 below. The municipality was established on 10th March, 1989 by a legislative instrument (LI) 1473. This was the period where Ghana adopted the District Assembly concept. The overall goal was to accelerate growth and development in the Municipality (Ghana Statistical service, October, 2014). 


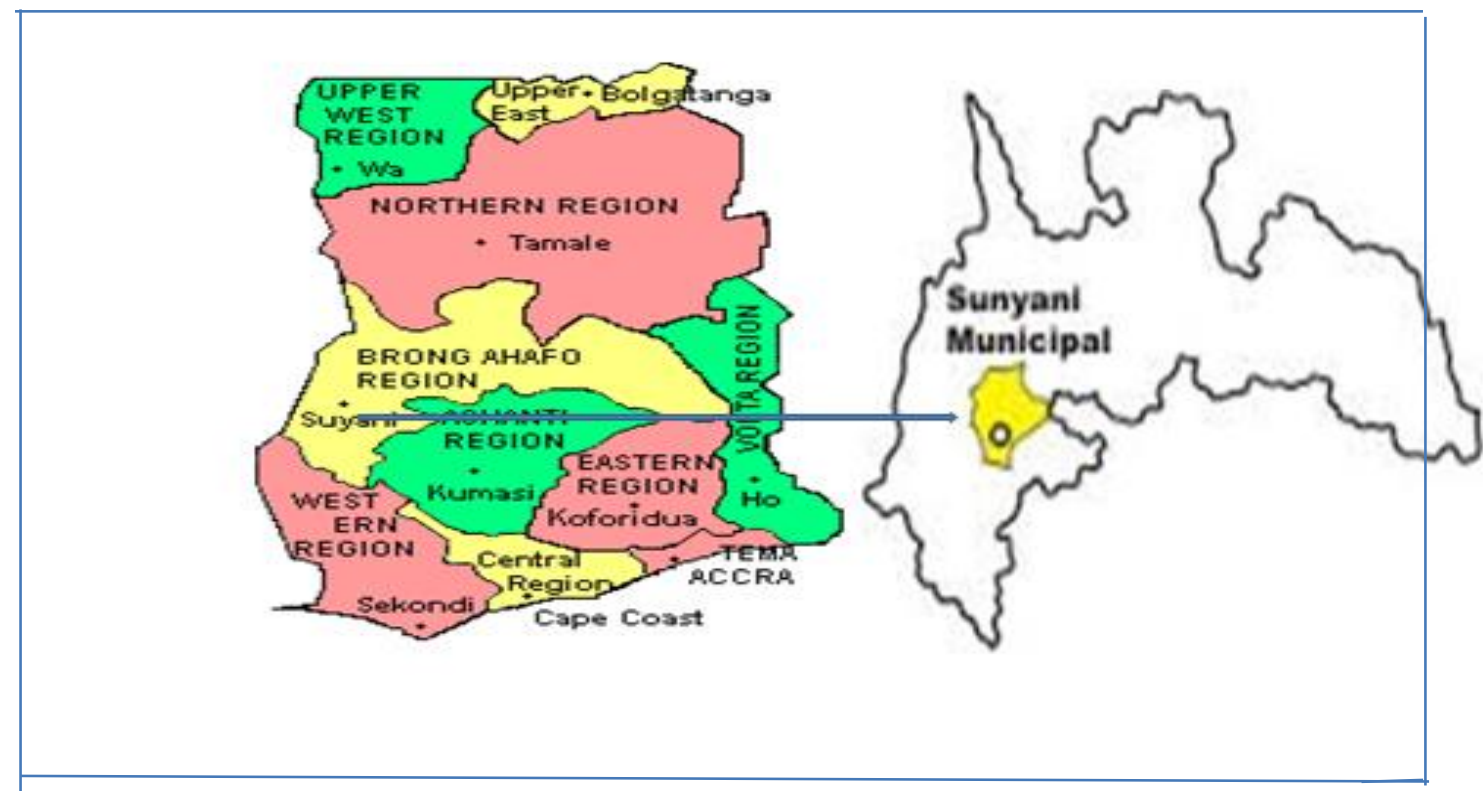

Figure 1. Map of ghana showing the map of ghana (left) and the brong ahafo region (right) with sunyani municipality (shaded inside the brong ahafo region)

\section{Ethical consent}

Ethical consent was obtained from the department ethical committee (DEC) of the hospital. Before the study commenced, a written informed consent were signed by all parties. During respondents' interview, respondents were made aware of the aim of the study and the rationale of the study. They were also assured of the confidentiality of both personal details and data except for the purpose of this study. Respondents who felt reluctant to continue the interview and wanted to withdraw at any stage were excluded from the study.

\section{Data collection}

Proteinuria and Blood pressure monitoring: The dip stick method described by (Pannu et al., 2014) were used to randomly monitor the protein levels of some 450 pregnant women who visited the BA Regional hospital between January 1 and December 2015. Similarly, with the help of trained Medical Laboratory technician, mercury sphygmomanometer were used to measure the diastolic and diastolic blood pressure of AN mothers during routine visits and recorded.

\section{Retrospective data}

Retrospective data on maternal mortality and mortality due to PIH (Eclampsia) between January 1, 2010 and 31 December 2015 were retrieved and recorded. Mothers who died at the hospital were first discussed at weekly and monthly mortality meetings. A gynecologist then filled in the death certificate and a data sheet for the data management unit of the hospital which included the clinical diagnosis at the time of death and some selected information were stored at the statistical unit. This was based on the cause of death agreed at the mortality meetings and it was usually supported by preliminary laboratory tests that had been done or the results of any other investigations carried out to confirm the diagnosis. Thus, the causes of death presented from there were based on consensus from the mortality meetings.

\section{Survey}

Simple random sampling technique were used to select 75 pregnant women at the AN clinic and 75 women who had delivered and attended postnatal $(\mathrm{PN})$ clinic. A structured written document was used to 
DOI: $10.21522 / \mathrm{TIJPH} .2013 .05 .04$. Art015

ISSN: $2520-3134$

interview them in twi and was transcribed into English. They were interviewed during their routine visits to the hospital every morning. Different set of women were interviewed as they had different dates of appointments. A code was given to respondents who were interviewed in other not duplicate respondents already interviewed. The same procedure were repeated on Tuesdays and Fridays which were for PN mothers. This were supported by focus group discussions and in-depth interviews.

\section{Data analysis}

Data on proteinuria, BP, retrospective records on maternal mortality as well as survey were separately entered manually in Microsoft Excel (2013). They were then individually analysed with Graph Pad prism version 4.0. Responses from AN mothers were however individually compared with their PN counterpart at $95 \%$ confidence interval with differences between categorical values at a $p$-value $<0.005$ being considered as significant.

\section{Results}

The study sought to analyse proteinuria and blood pressure (BP) of some 450 pregnant mothers who visited the AN section of the BA hospital during the study and analysis of the results showed that, $36 \%$ of these mothers had traces of protein in their urine as shown in Table 1 below. The study also showed that, 15 out of the 450 pregnant mothers tested were positive for proteinuria (Table 1). When the BP of pregnant mothers were also measured, the study showed that, $7.1 \%$ of these mothers had BPs outside the normal range (i.e., $\geq 90 / 130 \mathrm{mg} / \mathrm{Hg}$ ) as shown in Table 1 .

Table 1. Showing the category of protein in urine and blood pressure of some pregnant women during the period of the study at the brong ahafo regional hospital

\begin{tabular}{|l|l|l|}
\hline ATIVITY & Category of Test (N=450) & $\mathbf{n}(\%)$ \\
\hline Proteinuria & Positive & $15(3.3 \%)$ \\
\hline & Trace & $166(36.9 \%)$ \\
\hline $\begin{array}{l}\text { Blood Pressure (Systolic and } \\
\text { Diastolic) }\end{array}$ & Negative & $269(59.8 \%)$ \\
\hline & $\begin{array}{l}\text { Normal Range } \\
(\leq 90 / 130 \mathrm{mg} / \mathrm{Hg})\end{array}$ & $418(92.9 \%)$ \\
\hline & $\begin{array}{l}\text { Abnormal Range } \\
(\geq 90 / 130 \mathrm{mg} / \mathrm{Hg})\end{array}$ & $32(7.1 \%)$ \\
\hline
\end{tabular}

Footnote: $\mathrm{N}$ refers to the total number of pregnant mothers tested whiles $\mathrm{n}$ refers to the individual mothers under each activity.

The study also showed that, from January 1, 2010 to December, 31, 2015 a total of 75, $439(\mathrm{~N}=75,439)$ mothers attended the antennal section of the BA Regional Hospital as shown in Table 2 below. Out of this total number of visits, 139 of them $(0.18 \%)$ died due to different pregnancy related disorders and never returned to their husbands after birth. It was very surprising to note that, between 2010 and 2015, of the 139 death recorded, 37 of these $(26.61 \%)$ were due to eclampsia (Table 2$)$. The study further showed that, in the year 2015, (71.43\%) of all maternal deaths were due to eclampsia with the year 2012 recording the least percentage of maternal death $(13.29 \%)$ out of all maternal deaths for the period as shown in Table 2 below. 


\section{Among respondents}

Table 1. Showing total antenatal attendance, maternal mortality and maternal deaths due to eclampsia

\begin{tabular}{|c|c|c|c|c|c|c|c|}
\hline ACTIVITY & TOTAL & 2010 & 2011 & 2012 & 2013 & 2014 & 2015 \\
\hline Total Antenatal Attendance & $\mathrm{N} \dagger=75439$ & $\mathrm{~N}=12,491$ & $N=12,199$ & $N=13,312$ & $N=11,543$ & $N=12,704$ & $\mathrm{~N}=13,079$ \\
\hline & $n,(\%)$ & $n,(\%)$ & $n,(\%)$ & n, (\%) & $n,(\%)$ & $n,(\%)$ & $n,(\%)$ \\
\hline Maternal Mortality & $139(0.18 \%)$ & $20(0.16 \%)$ & $35(0.28 \%)$ & $35(0.26 \%)$ & $18(0.15 \%)$ & $14(0.11 \%)$ & $17(0.13 \%)$ \\
\hline $\begin{array}{l}\text { Percentage General maternal } \\
\text { Mortality out of Total Maternal } \\
\text { Attendance }\end{array}$ & $139(0.050 \%)$ & $20(0.16 \%)$ & $35(0.29 \%)$ & $35(0.29 \%)$ & $18(0.16 \%)$ & $14(0.11 \%)$ & $17(0.13 \%)$ \\
\hline $\begin{array}{l}\text { Percentage Maternal Mortality due } \\
\text { to Eclampsia out of Total Maternal } \\
\text { Death }\end{array}$ & $37(26.61 \%)$ & $3(15.00 \%)$ & $5(14.29 \%)$ & $10(28.57 \%)$ & $8(44.44 \%)$ & $6(42.86 \%)$ & $5(71.43 \%)$ \\
\hline
\end{tabular}

Note: $\mathrm{N}^{\mathrm{T}}$ Refers to the Total Number of Antenatal Mothers that visited the Regional Hospital; N Refers to the Total Antenatal Mothers for Each Respective year; $\mathrm{n}$ under Maternal Mortality Refers to Total Maternal Death; Figures in Percentages in Parentheses Refers to the Percentage Total Maternal Death.

The study also showed that, participants who responded to the structured questions consisted of only females who were more than 15 years of age and visited either the antenatal care (ANC) or the post natal care (PNC) section of the hospital between August and December 2015. Analysis of results with respect to age based on whether one was AN mother or PN mother showed that, greater majority of respondent were between ages 25-29, were AN mothers (34.67\%) compared to their PN counterpart (32.00\%) with a confidence interval of (0.4495 to 1.750) as shown in Table 3 below. The study also showed that, majority of the respondents from the ANC were domiciled in the Brong Ahafo Region, who were married but had attained education at least up to JSS (Junior Secondary School) level (Table 3). 
DOI: $10.21522 / \mathrm{TIJPH} .2013 .05 .04$. Art015

ISSN: $2520-3134$

Table 3. Stratification of post natal and anti natal mothers based on social demography among women at the sunyani regional hospital

\begin{tabular}{|c|c|c|c|c|c|c|c|}
\hline Variable & \% Post Natal (75) & \% Anti Natal(75) & \% Total (150) & P-Value & OR & $\mathrm{Cl}(95 \%)$ & Rel. Risk \\
\hline \multicolumn{8}{|l|}{ Age } \\
\hline$(15-19)$ & $5(6.67)$ & $1(1.33)$ & $6(8)$ & 0.0956 & 5.286 & 0.6021 to 46.40 & 1.714 \\
\hline$(20-24)$ & $6(8.00)$ & $11(14.67)$ & $17(22.67)$ & 0.1978 & 0.5059 & 0.3501 to 1.322 & 0.6803 \\
\hline$(25-29)$ & $24(32.00)$ & $26(34.67)$ & $50(66.67)$ & 0.729 & 0.8869 & 0.4495 to 1.750 & 0.9412 \\
\hline$(30-34)$ & $20(26.67)$ & $20(26.67)$ & $40(53.34)$ & 1 & 1 & 0.4802 to 2.082 & 1 \\
\hline$(35+)$ & $20(26.67)$ & $17(22.67)$ & $37(49.34)$ & 0.5699 & 1.241 & 0.5892 to 2.612 & 1.111 \\
\hline \multicolumn{8}{|l|}{ Region } \\
\hline$B / A$ & $64(85.33)$ & $62(82.67)$ & $126(84.00)$ & 0.656 & 1.22 & 0.6942 to 1.769 & 1.22 \\
\hline $\mathrm{N} / \mathrm{R}$ & $0(0.00)$ & $4(5.33)$ & $4(2.67)$ & 0.0426 & 0.1052 & 0.005561 to 1.991 & 0 \\
\hline UW/R & $1(1.33)$ & $5(6.67)$ & $6(4.00)$ & 0.0956 & 0.1892 & 0.02155 to 1.661 & 0.3243 \\
\hline UE/R & $0(0.00)$ & $2(2.67)$ & $2(1.33)$ & 0.1545 & 0.1947 & 0.009184 to 4.128 & 0 \\
\hline$A / R$ & $2(2.67)$ & $1(1.33)$ & $3(2.00)$ & 0.5598 & 1.342 & 0.1798 to 22.86 & 1.342 \\
\hline other specify & $8(10.67)$ & $1(1.33)$ & $9(6.00)$ & 0.0161 & 8.836 & 1.076 to 72.55 & 1.871 \\
\hline \multicolumn{8}{|l|}{ Occupation } \\
\hline Civil servant & $12(16)$ & $15(20)$ & $27(18.00)$ & 0.5237 & 0.7619 & 0.3297 to 1.761 & 0.8677 \\
\hline Trading & $25(33.33)$ & $25(33.33)$ & $50(33.33)$ & 1 & 1 & 0.7121 to 1.404 & 1 \\
\hline Farming & $6(8.00)$ & $3(4.00)$ & $9(6.00)$ & 0.3023 & 2.087 & 0.5019 to 8.678 & 1.362 \\
\hline Others, please specify? & $32(42.67)$ & $32(42.67)$ & $64(42.67)$ & 1 & 1 & 0.5235 to 1.910 & 1 \\
\hline \multicolumn{8}{|l|}{ Marital status } \\
\hline Married & $63(84.0)$ & $65(86.67)$ & $128(85.33)$ & 0.6444 & 0.8077 & 0.3257 to 2.003 & 0.9023 \\
\hline Single & $7(9.33)$ & $7(9.33)$ & $14(9300)$ & 1 & 1 & 0.5768 to 1.734 & 1 \\
\hline Divorced & $0(0.00)$ & $0(0.00)$ & $0(0.00)$ & - & _ & & _ \\
\hline Never Married & $5(6.67)$ & $3(4.00)$ & $8(5.33)$ & 0.4674 & 1.714 & 0.3945 to 7.449 & 1.268 \\
\hline \multicolumn{8}{|l|}{ Level of Education } \\
\hline No formal Education & $7(9.33)$ & $10(13.33)$ & $17(11.33)$ & 0.6444 & 0.6444 & 0.3257 to 2.003 & 0.9023 \\
\hline JSS Graduate & $43(57.33)$ & $28(37.33)$ & $71(47.33)$ & 0.0142 & 2.256 & 1.172 to 4.341 & 1.495 \\
\hline SSS Graduate & 11(14.67) & $16(21.33)$ & $27(18.00)$ & 0.288 & 0.6338 & 0.2721 to 1.476 & 0.783 \\
\hline Tertiary & 14(18.67) & $21(28.00)$ & $35(23.33)$ & 0.1766 & 0.5902 & 0.2735 to 1.274 & 0.7541 \\
\hline
\end{tabular}

Note: The following (B/A, N/R, UW/R, UE/R, A/R) means Brong Ahafo Region, Northern Region, Upper West Region, Upper East Region

\section{And ashanti region respectively; or means odds ratio, ci means confidence interval, rel. risk means} relative risk

As part of the study, maternal child bearing behavior, nulliparity and knowledge on pregnancy induced hypertension $(\mathrm{PIH})$ were investigated. Analysis of the data showed that, greater proportions of ANCmothers, i.e., (32.00\%) were nulliparous compared to their PN counterpart $(0 \%)$ and this was statistically significant $(\mathrm{p}<0.0001)$ as shown in Table 4. However, fewer proportions of PN mothers $(8.00 \%)$ were 
multiparous i.e., had already given birth to 4 children or more compared to PM (21.33\%) with an odds ratio of 2.271 and relative risk of 1.424 (Table 4).

It was also established that, greater majority of AN mothers (14.33\%) were hypertensive compared to the PN mothers $(5.33 \%)$ but this was not significant $(\mathrm{p}=0.0568)$ as shown in Table 4 . Knowledge of eclampsia was assessed as part of this research and the results showed that, greater proportions of the respondents of AN mothers (89.33\%) had no knowledge of this pregnancy disorder compared to the PN mothers $(46.67 \%)$. This was statistically significant ( $\mathrm{p}<0.0001$, CI [0.011 to 0.2475), Rel. Risk 0.4118). The study also showed that majority of AN mothers (89.33\%) had not seen a pregnant woman in seizure, neither had they (PN mothers) attended a talk on eclampsia in their life time.

When questions based on contraceptive use by mothers were posed, the results showed that, majority of AN mothers (84.00\%) were not bothered about this birth control method compared to their PN mothers (74.67\%) but this was not statistically significant ( $\mathrm{p}=0.1581)$. Greater majority of PN mothers $(25.33 \%)$ however confirmed they were on some kind of family planning policy compared to AN mothers (16.00\%) ( $p>0.05, \mathrm{OR}=2.93$ ) as shown in Table 4 below. When issues of family history on some hereditary related diseases were discussed, the study results showed that, majority of AN mothers were diabetic (12.00\%) compared to PN counterpart $(9.33 \%)$. In addition, the study showed that, greater majority of AN-mothers (2.67\%) had cardiac related disease compared to their PN colleagues $(1.00 \%)$ although the difference was not significant $(\mathrm{p}=0.5598)$ as shown in Table 4 . This was also seen with sickle-cell status of the mothers who responded to the questionnaires (AN-mothers [9.33\%] vs. PN mothers [2.67\%]) (Table 4). In relation to whether a relative has been diagnosed of pregnancy induced hypertension $(\mathrm{PIH})$ before, it was evenly distributed. Eight percent (8\%) of both antenatal and postnatal mothers confirmed they had been diagnosed of $\mathrm{PIH}$ in during their pregnancy. 
DOI: 10.21522/TIJPH.2013.05.04.Art015

ISSN: $2520-3134$

Table 4. Stratification of post natal and anti natal mothers based on maternal health history and knowledge on eclampsia among women at the sunyani regional hospital

\begin{tabular}{|c|c|c|c|c|c|c|c|}
\hline Variable & \% Postnatal (75) & $\%$ Antinatal(75) & \% Total (150) & P-Value & OR & $\mathrm{Cl}(95 \%)$ & Rel Risk \\
\hline \multicolumn{8}{|c|}{ How many births have you had? } \\
\hline 1 & $20(26.67)$ & $16(21.33)$ & $36(24.00)$ & 0.4444 & 1.341 & 0.6313 to 2.848 & 1.152 \\
\hline 2 & $28(37.33)$ & $19(25.33)$ & $47(31.33)$ & 0.1131 & 1.756 & 0.8720 to 3.536 & 1.306 \\
\hline 3 & $11(14.67)$ & $10(13.33)$ & $21(14.00)$ & 0.814 & 1.117 & 0.4437 to 2.813 & 1.056 \\
\hline 4 & $16(21.33)$ & $6(8.00)$ & $22(14.67)$ & 0.0748 & 2.271 & 0.9067 to 5.689 & 1.424 \\
\hline Not yet & $0(0.00)$ & $24(32.00)$ & $24(16.00)$ & $<0.0001$ & 0.01392 & 0.0008 too. 234 & 0 \\
\hline \multicolumn{8}{|c|}{ How many pregnancies have you had? } \\
\hline 1 & $13(17.33)$ & $18(24.00)$ & $31(20.67)$ & 0.3133 & 0.664 & 0.2986 to 1.476 & 0.8049 \\
\hline 2 & $17(22.67)$ & $16(21.33)$ & $33(22.00)$ & 0.8437 & 1.081 & 0.4989 to 2.342 & 1.039 \\
\hline 3 & $19(25.33)$ & $22(29.33)$ & $41(27.33)$ & 0.5826 & 0.8174 & 0.3979 to 1.679 & 0.902 \\
\hline 4 and Above & $26(34.67)$ & $19(25.33)$ & $45(30.00)$ & 0.2819 & 1.474 & 0.7259 to 2.992 & 1.205 \\
\hline \multicolumn{8}{|l|}{ Are you hypertensive? } \\
\hline Yes & $4(5.33)$ & $11(14.33)$ & $15(10.00)$ & 0.0568 & 0.3278 & 0.0994 to 1.081 & 0.507 \\
\hline No & $71(94.67)$ & $64(85.33)$ & $135(90.00)$ & 0.0568 & 3.051 & 0.9249 to 10.06 & 1.972 \\
\hline \multicolumn{8}{|c|}{ Have you ever heard of Eclampsia before? } \\
\hline Yes & $40(53.33)$ & $8(10.67)$ & $48(32.00)$ & $<0.0001$ & 9.571 & 4.041 to 22.67 & 2.429 \\
\hline No & $35(46.67)$ & $67(89.33)$ & $102(68.00)$ & $<0.0001$ & 0.1045 & 0.044 to 0.2475 & 0.4118 \\
\hline \multicolumn{8}{|c|}{ Have you ever seen a pregnant woman in seizure before? } \\
\hline Yes & $9(12.00)$ & $8(10.67)$ & $17(11.33)$ & 0.7967 & 1.142 & 0.4153 to 3.140 & 1.067 \\
\hline No & $66(88.0)$ & $67(89.33)$ & $131(87.33)$ & 0.7967 & 0.8756 & 0.3185 to 2.408 & 0.9373 \\
\hline \multicolumn{8}{|c|}{ Have you ever benefitted from a talk on Eclampsia before? } \\
\hline Yes & $27(36.0)$ & $12(16.00)$ & $39(26.00)$ & 0.0052 & 2.953 & 1.358 to 6.423 & 1.601 \\
\hline No & $48(64.00)$ & $63(84.00)$ & $101(67.33)$ & 0.0052 & 0.3386 & 0.156 to 0.7365 & 0.6246 \\
\hline \multicolumn{8}{|c|}{ Are you on any family planning policy? } \\
\hline Yes & $19(25.33)$ & $12(16.00)$ & $31(20.66)$ & 0.1581 & 1.781 & 0.7943 to 3.994 & 1.302 \\
\hline No & $56(74.67)$ & $63(84.00)$ & $119(79.33)$ & 0.1581 & 0.5614 & 0.2503 to 1.259 & 0.7678 \\
\hline \multicolumn{8}{|c|}{ Have you ever had any of the below medical conditions before? } \\
\hline Hypertension & $2(2.67)$ & $5(6.67)$ & $7(4.67)$ & 0.2455 & 0.3836 & 0.07201 to 2.043 & 0.5597 \\
\hline Diabetes & $1(1.33)$ & $0(0.00)$ & $1(0.67)$ & 0.3157 & 3.04 & 0.1218 to 75.89 & 2.014 \\
\hline Cardiac Disorder & $1(1.33)$ & $1(1.33)$ & $2(1.33)$ & 1 & 1 & 0.06135 to 16.30 & 1 \\
\hline Renal disorder & $0(0.00)$ & $0(0.00)$ & $0(0.00)$ & & & & \\
\hline Anaemia & $1(1.33)$ & $1(1.33)$ & $2(1.33)$ & 1 & 1 & 0.06135 to 16.30 & 1 \\
\hline None of the above & $70(93.33)$ & $68(90.67)$ & $138(92.00)$ & 0.5472 & 1.441 & 0.4360 to 4.763 & 1.217 \\
\hline \multicolumn{8}{|c|}{ Have you ever been diagnosed of any of hese conditions during pregnancy before? } \\
\hline Yes & $5(6.67)$ & $5(6.67)$ & $10(6.67)$ & 1 & 1 & 0.2771 to 3.609 & 1 \\
\hline No & $70(93.33)$ & $70(93.33)$ & $140(93.33)$ & 1 & 1 & 0.2771 to 3.609 & 1 \\
\hline \multicolumn{8}{|c|}{ If yes, when was your first time you were diagnosed of this condition? } \\
\hline less than 1 year & $3(4.00)$ & $3(4)$ & $6(1.33)$ & 1 & 1 & 0.1952 to 5.123 & 1 \\
\hline 1-2 Years & $0(0.00)$ & $2(2.67)$ & $2(1.33)$ & 0.1545 & 0.1947 & 0.0092 to 4.128 & 0 \\
\hline 3-4 years & $0(0.00)$ & $0(0.00)$ & $0(0.00)$ & & & & \\
\hline 5 years above & $2(2.67)$ & $0(0.00)$ & $2(1.33)$ & 0.1545 & 5.136 & 0.2423 to 108.9 & 2.027 \\
\hline Never/none & $70(93.33)$ & $70(40.00)$ & $140(93.33)$ & 1 & 1 & 0.2771 to 3.609 & 1 \\
\hline \multicolumn{8}{|c|}{ Have you ever been on contraceptives before? } \\
\hline Yes & $28(37.33)$ & $28(37.033)$ & $54(36.00)$ & 1 & 1 & 0.5159 to 1.938 & 1 \\
\hline No & $47(62.67)$ & $47(62.67)$ & $94(62.67)$ & 1 & 1 & 0.5159 to 1.938 & 1 \\
\hline \multicolumn{8}{|c|}{ Before this pregnancy were you normal, over weight or obese? } \\
\hline Yes & $62(82.67)$ & $62(82.67)$ & $124(82.67)$ & 1 & 1 & 0.4292 to 2.330 & 1 \\
\hline No & $13(17.33)$ & $12(16.00)$ & $25(16.67)$ & 0.8266 & 1.101 & 0.4660 to 2.600 & 1.048 \\
\hline Not Remember & $\mathrm{O}(0.00)$ & $1(1.33)$ & $1(0.67)$ & 1 & 1 & 0.06135 to 16.30 & \\
\hline \multicolumn{8}{|c|}{ Do you have any family history of the following diseases? } \\
\hline Diabetes & $7(9.33)$ & $9(12.00)$ & $16(16.67)$ & 0.2197 & 0.5404 & 0.2001 to 1.459 & 0.7098 \\
\hline Hypertension & $12(16.00)$ & $9(12.00)$ & $21(10.67)$ & 0.4802 & 1.397 & 0.5506 to 3.543 & 1.17 \\
\hline Cardiac disease & $1(1.00)$ & $2(2.67)$ & $0(0.00)$ & 0.5598 & 0.4932 & 0.0437 to 5.562 & 0.6622 \\
\hline Renal disease & $0(0.00)$ & $0(0.00)$ & $0(0.00)$ & & & & \\
\hline Sickle cell disease & $2(2.67)$ & $7(9.33)$ & $9(6.00)$ & 0.0856 & 0.2661 & 0.0534 to 1.326 & 0.4292 \\
\hline None of the above & $48(64.00)$ & $44(58.67)$ & $92(61.33)$ & 0.5027 & 1.253 & 0.6483 to 2.420 & 1.121 \\
\hline Diabetes/Hypertension & $5(6.67)$ & $4(5.33)$ & & 0.731 & 1.268 & 0.3267 to 4.920 & 1.119 \\
\hline \multicolumn{8}{|c|}{ Has any relative of yours been diagnosed of pregnancy induced hypertension before? } \\
\hline Yes & $6(8.00)$ & $6(8.00)$ & $12(8.00)$ & 1 & 1 & 0.3073 to 3.255 & 1 \\
\hline No & $69(92.00)$ & $69(92.00)$ & $138(92.00)$ & 1 & 1 & 0.3743 to 2.671 & 1 \\
\hline
\end{tabular}


Family planning usage among mothers before conception were compared based on whether a respondent was an $\mathrm{AN}$ - or PN-mother and analysis of the results showed that, fewer proportion of AN mothers used all the different categories of birth control methods compared to the PN mothers. The study also showed that, majority of antenatal mothers 5 (33\%) resorted to condom use during sex with their partners as shown in Figure 2 below (Appendix 1).

It was further revealed that, the use of cervical cap and female sterilization was not common among antenatal mothers. The study showed that after condom use as birth control mechanism, both norplant and the pill came second in terms of patronage among AN mothers (4\%) as shown in appendix 1

AN respondents to this study also showed that, after the use of condom for birth control, norplant and the pill come second (Figure 2). The study also showed that, majority of the postnatal mothers 74.67\% relied on conception for birth control compared to their antenatal counterpart (Appendix 1). With respect to the particular contraceptive method usage, usage of Depo provera was the mostly used method among the postnatal respondents (58\%). It was followed by the pill with $16 \%$, condom recorded $11 \%$, cervical cap and Norplant had 5\% each.

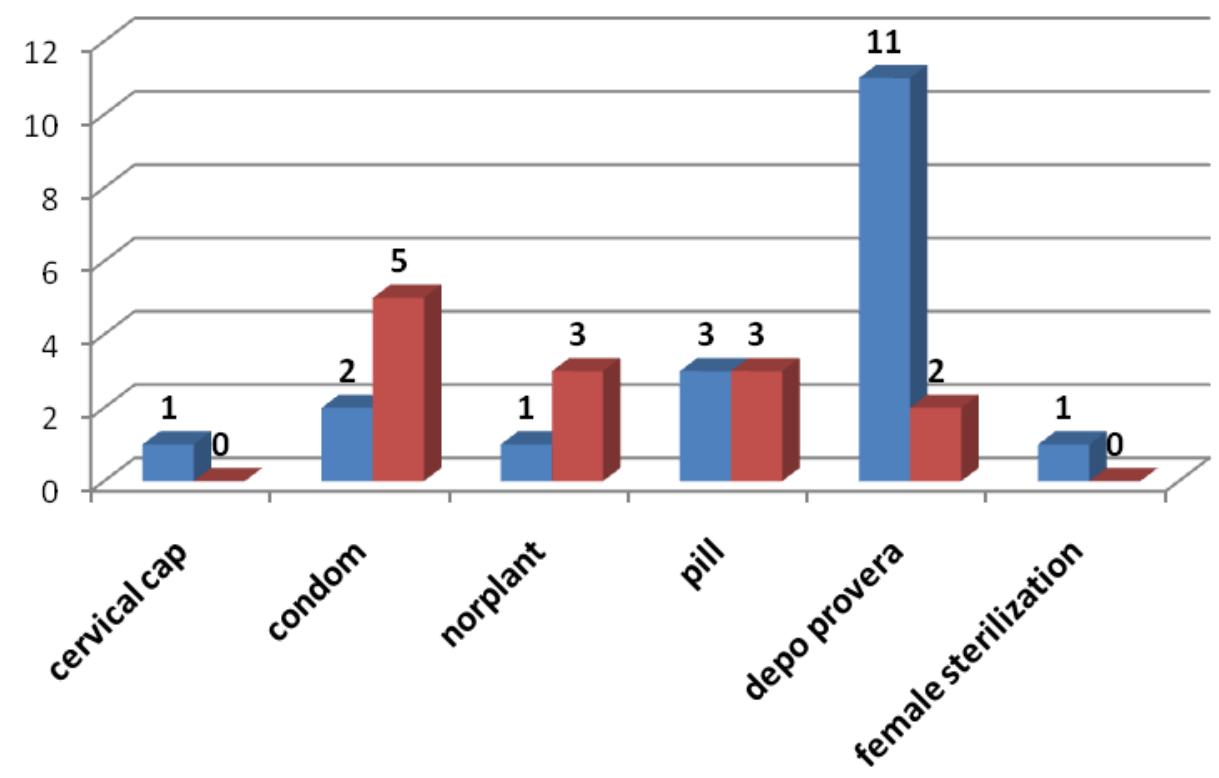

Postnatal

Antenatal

The nutritional behavior of respondents were also assessed as part of the study and it was established that, greater majority of the AN mothers fed on fat based diet (50.67\%) compared to their PN colleagues $(40.00 \%)$ as shown in Table 4 below ( $\mathrm{p}=0.1895$; $\mathrm{OR}=0.6491$; Rel Risk=0.8039). Fewer proportions of these AN mothers however consumed high amount of salt in their diet (6.67\%) and were hesitant in adding salt to already prepared food on the dining table (50.67\%) (Table 4). The study also showed that, fewer proportions of AN mothers underwent exercise during pregnancy (50.67\%) compared to (56.00\%) of PN mothers. This was however not statistically significant. It was obvious from this study that both AN and PN mothers were not smokers. However, greater majority of the spouses of PN mothers were smokers (4.00\%) compared to their AN counterpart with Odds Ratio of 1.52 and Relative Risk of 1.208 as shown in Table 4. With respect to alcoholic beverages intake, the study showed an even distribution among both ANand PN mothers. 
DOI: $10.21522 /$ TIJPH.2013.05.04.Art015

ISSN: $2520-3134$

Table 4. Stratification of post natal and ante natal mothers based on nutrition and habits among women at the sunyani regional hospital

\begin{tabular}{|c|c|c|c|c|c|c|c|}
\hline Variable & \% Post Natal & \% Antenatal & \% Total & p-Value & Odds Ratio & $\mathrm{Cl}(95 \%)$ & Rel Risk \\
\hline \multicolumn{8}{|c|}{ Do you eat fatty foods? } \\
\hline Yes & $30(40.00)$ & $38(50.67)$ & $68(64.76)$ & 0.1895 & 0.6491 & 0.3399 to 1.240 & 0.8039 \\
\hline No & $45(60.00)$ & $37(49.33)$ & $82(54.67)$ & 0.1895 & 1.541 & 0.8067 to 2.942 & 1.244 \\
\hline \multicolumn{8}{|c|}{ Do you usually eat food with } \\
\hline Moderate salt & $66(88.00)$ & $68(90.67)$ & 134(89.33) & 0.5968 & 0.7549 & 0.2656 to 2.145 & 0.8756 \\
\hline Plenty salt & $8(10.67)$ & $5(6.67)$ & $13(8.67)$ & 0.3979 & 1.647 & 0.5130 to 5.288 & 1.249 \\
\hline Without salt at all & $1(1.33)$ & $2(2.67)$ & $3(2.00)$ & 0.5598 & 0.4932 & 0.0434 to 5.562 & 0.6622 \\
\hline \multicolumn{8}{|c|}{ Do you add salt to food before eating at table? } \\
\hline Yes & $42(56.00)$ & $38(50.67)$ & $80(53.33)$ & 0.5598 & 0.4932 & 0.0437 to 5.562 & 0.6622 \\
\hline No & $33(44.00)$ & $37(49.33)$ & $70(46.67)$ & 0.5598 & 0.4932 & 0.0437 to 5.562 & 0.6622 \\
\hline \multicolumn{8}{|l|}{ Do you exercise? } \\
\hline Yes & 40(53.33) & $38(50.67)$ & $78(52.00)$ & 0.7438 & 1.113 & 0.5862 to 2.113 & 1.055 \\
\hline No & $35(46.67)$ & $37(49.33)$ & $72(48.00)$ & 0.7438 & 0.8986 & 0.4734 to 1.706 & 0.9479 \\
\hline \multicolumn{8}{|c|}{ How often do you exercise? } \\
\hline Once a week & $6(10.67)$ & $8(10.67)$ & 14(9.33) & 0.5746 & 0.7283 & 0.2398 to 2.212 & 0.8447 \\
\hline Twice a week & $8(16.00)$ & $12(16.00)$ & $20(13.33)$ & 0.0748 & 0.4403 & 0.1758 to 1.103 & 0.6269 \\
\hline 3 Times a week & $9(17.33)$ & $13(17.33)$ & $22(14.67)$ & 0.3559 & 0.6503 & 0.2597 to 1.629 & 0.7934 \\
\hline Other & $11(6.67)$ & $5(6.67)$ & $16(10.67)$ & 0.1125 & 2.406 & 0.7927 to 7.304 & 1.439 \\
\hline None of the above & $41(49.33)$ & $37(49.33)$ & $78(52.00)$ & 0.5133 & 1.238 & 06519 to 2.353 & 1.113 \\
\hline \multicolumn{8}{|l|}{ Do you smoke? } \\
\hline Yes & $0(0.00)$ & $0(0.00)$ & $0(0.00)$ & Nil & Nil & Nil & Nil \\
\hline No & $75(100.00)$ & $75(100)$ & 150(100) & $\mathrm{Nil}$ & $\mathrm{Nil}$ & $\mathrm{Nil}$ & $\mathrm{Nil}$ \\
\hline \multicolumn{8}{|c|}{ If yes, how long did you smoke? } \\
\hline Less than 5 years & $0(0.00)$ & $0(0.00)$ & $0(0.00)$ & Nil & Nil & $\mathrm{Nil}$ & $\mathrm{Nil}$ \\
\hline 6-10 years & $0(0.00)$ & $0(0.00)$ & $0(0.00)$ & $\mathrm{Nil}$ & Nil & $\mathrm{Nil}$ & Nil \\
\hline Above 10 years & $0(0.00)$ & $0(0.00)$ & $0(0.00)$ & Nil & $\mathrm{Nil}$ & $\mathrm{Nil}$ & $\mathrm{Nil}$ \\
\hline None & $75(100.00)$ & $75(100)$ & $150(0.00)$ & Nil & Nil & $\mathrm{Nil}$ & $\mathrm{Nil}$ \\
\hline \multicolumn{8}{|c|}{ Does your husband smoke currently? } \\
\hline Yes & $3(4.00)$ & $2(2.67)$ & $5(3.33)$ & 0.6492 & 1.521 & 0.2467 to 9.377 & 1.208 \\
\hline No & $72(96.00)$ & $73(97.33)$ & $145(138.10)$ & 0.6492 & 0.6575 & 0.1066 to 4.054 & 0.8276 \\
\hline \multicolumn{8}{|c|}{ Have you ever drunk alcohol? } \\
\hline Yes & $14(18.67)$ & 14(18.67) & $28(18.67)$ & 1 & 1 & 0.4397 to 2.274 & 1 \\
\hline No & $61(81.33)$ & $61(81.33)$ & $122(81.33)$ & 1 & 1 & 0.4397 to 2.274 & 1 \\
\hline \multicolumn{8}{|l|}{ Do you drink alcohol? } \\
\hline Yes & $3(4.00)$ & $3(4.00)$ & $6(2.00)$ & 1 & 1 & 0.1952 to 5.123 & 1 \\
\hline No & $72(96.00)$ & $72(96.00)$ & $144(96.00)$ & 1 & 1 & 0.1952 to 5.123 & 1 \\
\hline \multicolumn{8}{|l|}{ Were you alcoholic? } \\
\hline Yes & $3(4.00)$ & $3(4.00)$ & $6(4.00)$ & 1 & 1 & 0.1952 to 5.123 & 1 \\
\hline No & $72(96.00)$ & $72(96.00)$ & $144(96.00)$ & 1 & 1 & 0.1952 to 5.123 & 1 \\
\hline
\end{tabular}




\section{Discussion}

The challenges of maternal mortality has been an issue of great concern for some time now especially among developing nations of Africa, South America and Asia. This is evident by data published by the WHO and other International bodies (WHO, 2011). This is the first time a study on the relationship between PIH, BP and maternal mortality has been conducted at the ANC section of the Brong Ahafo Regional hospital, Sunyani.

The greater majority of ANC- mothers who had traces of protein in their urine was very worrying. Especially troubling was 32 out of 450 ANC-mothers recording high systolic and diastolic blood pressure during the study. It has been known through research that criteria adopted for women with proteinuria alone could not be diagnosed as having preeclampsia until mothers exhibit hypertension; in many developed countries including Japan, pregnant mothers who do not develop hypertension are often diagnosed as having gestational proteinuria. As a results gestational proteinuria has been adopted for retrospective diagnosis. These criteria may have been based on the belief that clinical presentation of preeclampsia involves initial hypertension and subsequent proteinuria (Takahiro et al., 2011).

Our study has also shown that, maternal mortality among the antenatal visitors to the Regional Hospital has been high compared to the developed regions of the world. This has reflected in recording a high eclampsia related mortality within the Regional Hospital. This observation did not come as a surprised. It has been published earlier by the Maternal Mortality Estimation Inter-Agency Group (MMEIAG) of the World Health Organization (WHO) where it is being estimated that Ghana's maternal mortality rate has gone up from 350 per 100,000 live births to 380 (WHO, 2015). This report also indicated that in 2013, an estimated 3,100 women died from pregnancy related causes and that figures from the District Health Management Information System has revealed that 1,012 pregnant women died in 2013 from pregnancy related issues across the country (Anon. 2, 2016). This may have translated in producing a high maternal mortality and mortality due to eclampsia in Brong Ahafo Regional Hospital. In addition, because risk factors of eclampsia are not fully understood, strategies for the prevention of eclampsia globally are also limited.

Given this situation, there ought to be a focus on prevention and this could be done primarily by preventing the development of pre or secondary eclampsia by using pharmacologic agents that prevent convulsions in women with established preeclampsia. Prevention could also be tertiary by preventing subsequent convulsions in women with established eclampsia. Currently, there is no preventive therapy for preeclampsia. During the past decade, several randomized trials reported on the use of protein or salt restricting zinc, magnesium, or fish oil supplementation, low-dose aspirin, calcium, and vitamin $\mathrm{C}$ as well as vitamin $\mathrm{E}$ in women with various risk factors to reduce the rate or severity of preeclampsia (Sibai, 2005). However, the results of these studies have been a subject of a recent review. In a follow up study to assess the level of awareness of pregnancy related disorders including eclampsia, the relatively higher proportion of respondents who lived in Sunyani, who had married and were educated at least up to the Junior Secondary School (JSS) level was expected. Information gathered during focus group discussions showed that, mothers were comfortable attending ANC care with Health facilities within close proximity. They were of the opinion that, in case of pregnancy induced emergencies, mothers need not risk their life travelling longer distances before assessing health care. It also came to light during in depth interviews with some selected mothers that, pregnant mothers without legitimately married husbands were stigmatized. This perception may have informed the decision of greater majority of ANC mothers getting married before conception. In addition, the BA Regional Hospital is situated in Sunyani which is a regional capital with an avalanche of Junior and Senior Secondary Schools scattered all over the city in addition 1 Polytechnic and 2 Universities. It therefore did not come as surprise that majority of the ANCresponding mothers were educated at least up JSS level. This accession was in line with earlier study (Conde-Agudelo and Belzian, 2000).

The greater number of nulliparous mothers attending ANC sections during the survey compared to their multiparous not comes as surprise. There has been an observation that, multiparous mothers 
DOI: $10.21522 / \mathrm{TIJPH} .2013 .05 .04$. Art015

ISSN: $2520-3134$

obviously had experience with respect to pregnancy-related matters and were generally not too bothered by attending ANC during pregnancy. In addition, there have been studies linking nulliparity and eclampsia in pregnant mothers. In one such study, the aim was to develop a predictive model for preeclampsia cases among pregnant women based on clinical risk factors for nulliparous women to identify a subgroup at risk by a group of researchers (North et al., 2011).

The results of the study showed that, the most important clinical risk factors for pre-eclampsia was in healthy nulliparous women compared to their multiparous counterpart. This study provided a new information on the level of risk associated with specific combinations of risk factors. The predictive performance of the algorithm was modest, but offered a considerable improvement on current practice in healthy nulliparous women. As all known risk factors were included in this large prospective cohort, the study showed that the expected performance and limitations of using clinical phenotype to predict preeclampsia. This algorithm served as a prototype that requires validation in other nulliparous populations. If validated, it might provide a personalised clinical risk profile for nulliparous women to which biomarkers could be added (Kenny et al. 2014). This assertion supported results of this present study.

Our study showed that, greater majority of the responding mothers were hypertensive among ANCmothers. Several studies conducted and which have been dully published have linked pregnancy induced hypertension as a risk factor for the development of eclampsia. It has been reported that, pre-eclampsia and gestational hypertension are characterized by the new onset of hypertension $(>140 \mathrm{mmHg}$ systolic or $>90 \mathrm{mmHg}$ diastolic) after 20 weeks gestation (Redman and Russell, 2010). This study also shows that, it is important to have normal blood pressure recorded either for pre-pregnancy or at least in early pregnancy. The study reiterated that, a normal first blood pressure measured between 16 and 20 weeks could result in a missed diagnosis of chronic hypertension. In fact, when women are presented with hypertension in pregnancy after 20 weeks gestation and the earlier blood pressure is unknown, the woman ought to be managed as if she had gestational hypertension or pre-eclampsia and appropriate investigations carried out done after pregnancy to determine if there is an underlying chronic hypertension (Fernanda et al., 2014).

The research further showed that, fewer proportion of ANC- mothers used contraceptives for birth control before conception compared to their PN mothers. The aim of this question was to assess whether the use of a particular contraceptive was linked with pre-eclampsia symptoms. The study showed that majority of antenatal mothers used condom, followed by the pill and norplant. Gratacos et al conducted a study published in 1996 that sought to answer the question of whether the use of contraception had the tendency to reduce pregnancy-induced hypertension. This was the estimation of the impact of the exposure to spermatozoa on the risk of developing pre eclampsia symptoms among some primigivid women. The result of the study showed that, the duration of unprotected sexual cohabitation was approximately $50 \%$ shorter in women with pregnancy induced hypertension $(2.3$ verses $4.7, \mathrm{p}<0.0001)$ regardless of the contraception being used. The results of this study further showed that, the risk of pre eclampsia in primividae women were reduced with the duration of sexual cohabitation, and therefore with the exposure to paternal spermatozoa. However, the protective effect of exposure is not achieved whiles using the pill. In summary, the study revealed that, contraception does not appear to be a viable public health policy to reduce the risk of pre eclampsia symptoms among ANC-mothers.

As part of this study, the nutritional habit of mothers based on whether one was ANC- or PNC- mother were assessed and the study showed greater majority of ANC-mothers consumed fatty diet and eat with moderate amount of salt. It has been reported earlier that, hypertensive disorders of pregnancy (HDPs), including gestational hypertension and pre-eclampsia, are common obstetric complications associated with adverse health outcomes for the mother and child (Magee et al; 2014). It however remains unclear how dietary intake influenced HDP risk. To answer this question the associations between pre-pregnancy dietary patterns and risk of HDPs was investigated (Magee et al., 2014). Using 3,582 women selected in the Australian Longitudinal Study on Women's Health, in an observational population-based study. 
In this study, diet was assessed by using a validated 101-item food-frequency questionnaire in 2003, and factor analysis were used to identify dietary patterns. HDPs were assessed by using the question, "Were you diagnosed or treated for hypertension during pregnancy?" Generalized estimating equation models were used to estimate RRs (95\% CIs) adjusted for dietary, reproductive, socio-demographic, and lifestyle factors. The study identified 4 dietary patterns labeled as meat, high-fat, and sugar; Mediterranean style; fruit and low-fat dairy; and cooked vegetables. In the adjusted model, the meat, high-fat, and sugar, fruit and low-fat dairy and cooked vegetable dietary patterns were not associated with HDP risk. The Mediterranean-style dietary pattern (characterized by vegetables, legumes, nuts, tofu, rice, pasta, rye bread, red wine, and fish) were also inversely associated with risk of developing HDPs (quartile 4 compared with quartile $1: \mathrm{RR}, 0.58 ; 95 \% \mathrm{CI}, 0.42,0.81)$. The study conclude that, the population-based study of Australian women, was observed as an independent protective dose-response association between pre-pregnancy consumption of a Mediterranean-style dietary pattern and HDP risk.

\section{Conclusion}

Results of the study have shown that, maternal mortality among ANC-mothers visiting the BA Regional Hospital is generally high. This could be as a result of elevated systolic and diastolic blood pressure in addition to high levels of trace amount of protein in the urine of pregnant mothers visiting the AN section of the hospital. It has been earlier reported that risk factors for preeclampsia has included medical conditions with the potential to cause microvascular disease (e.g., diabetes mellitus, chronic hypertension, vascular and connective tissue disorders), antiphospholipid antibody syndrome, and nephropathy. This has been augmented with the notion that other risk factors are pregnancy itself or may be specific to the mother or father of the fetus which require further research into collate empirical data. It is therefore being recommended that, education needs to be intensified to enlighten pregnant mothers about risk factors of PIH and possible eclampsia. This could trigger a change in behavioural pattern to control the rate of maternal death due to eclampsia.

\section{References}

[1].(Anon 1) http://www.graphic.com.gh/news/general-news/35688-maternal-mortality-rate-increases-in-ghanareport.html.

[2].Annon1. 2016 (www.ghanahealthservice.org/category.php?hid=2\&cid=8) Date visited Feb. 2016.

[3].Baha M. Sibai, MD (2005) Diagnosis, Prevention, and Management of Eclampsia, the American College of Obstetricians and Gynecologist, VOL. 105, NO. 2, FEBRUARY $2005 \quad 402$ (c) 2005. doi:10.1097/01.AOG.0000152351.13671.99

[4].Chames MC, Livingston JC, Invester TS, Barton JR, Sibai BM (2002). Late postpartum eclampsia: a preventable disease? Am J Obstet Gynecol 2002; 186:1174 -7.

[5].Conde-Agudelo A, Belizán JM (2000) Maternal morbidity and mortality associated with interpregnancy interval: cross sectional study. BMJ. 2000 Nov 18; 321 (7271):1255-9. PMID: 11082085, PMCID: PMC27528, http://www.ncbi.nlm.nih.gov/pubmed/11082085

[6].Fernanda B. C, Letícia G. P, Augusto K. M, Giovani G I C. Antonello, H D. Mistry, Carlos E. Poli-deFigueiredo, Bartira E. Pinheiro da Costa (2014) is there any relationship between ABO/Rh blood groupand patients with pre-eclampsia? Pregnancy Hypertension: An International Journal of Women's Cardiovascular Health 4 (2014) 170-173, International Journal of cardiovascular Health, http://dx.doi.org/10.1016/j.preghy.2014.03.00322107789/www.elsevier.com/locate/preghy./

[7].Kenny L C., Black M A., Poston L, Taylor R, Myers J E., Baker P N., McCowan L M., Simpson Nigel A.B., Dekker G A., Roberts C T., Rodems K, Noland B, Raymundo M, Walker J J., North R A ( 2014). Early Pregnancy Prediction of Preeclampsia in Nulliparous Women, Combining Clinical Risk and Biomarkers, Hypertension. 2014;64:644-652DOI:10.1161/HYPERTENSIONAHA.114.03578.

[8].Magee L A., Pels A, Winnipeg H M, Rey E, Dadelszen P v .(2014) Diagnosis, Evaluation, and Management of the Hypertensive Disorders of Pregnancy: Executive Summary, J Obstet Gynaecol Can 2014;36(5):416-438, http://sogc.org/wp-content/uploads/2014/05/gui307CPG1405E1.pdf. 
DOI: $10.21522 / \mathrm{TIJPH} .2013 .05 .04$. Art015

ISSN: $2520-3134$

[9].Mammaro A, Carrara S, Cavaliere A, Ermito S, Dinatale A, Pappalardo E M, Militello M, and Pedata R (2009). Hypertensive Disorders of Pregnancy, Prenat Med. 2009 Jan-Mar; 3(1): 1-5, PMCID: PMC3279097.

[10]. North R A, McCowan Lesley M E,Dekker Gustaaf A, Poston Lucilla, Chan Eliza H Y, Stewart Alistair W, Black Michael A, Taylor Rennae S, Walker James J, Baker Philip N, Kenny Louise C, (2011). Clinical risk prediction for pre-eclampsia in nulliparous women: development of model in international prospective cohort Research BMJ 2011; 342 doi: http://dx.doi.org/10.1136/bmj.d1875 (Published 07 April 2011) Cite this as: BMJ 2011; 342:d1875.

[11]. Pannu D, Das B, Hazari P, Maternal and perinatal outcome in eclampsia and factors affecting the outcome: a study in North Indian population. Int J Reprod Contracept Obstet Gynecol. 2014; 3(2): 347-351. doi:10.5455/23201770.ijrcog20140612.

[12]. Sibai BM. VOL. 105, NO. 2, FEBRUARY 2005402 () 2005 by the American College of Obstetricians and Gynecologists. 0029-7844/05/\$30.00 Published by Lippincott Williams \& Wilkins. doi:10.1097/01.AOG.0000152351.13671.99.

[13]. Steven J. Wagner, Letitia A. Acquah, E. Paul Lindell, Iasmina M. Craici, Majken T. Wingo, Carl H. Rose, Wendy M. White, Phyllis August and Vesna D. Garovic (2011). Posterior Reversible Encephalopathy Syndrome and Eclampsia: Pressing the Case for More Aggressive Blood Pressure Control, Mayo Clin Proc. 2011 Sep; 86(9): 851-856. doi: 10.4065/mcp.2011.0090, PMCID: PMC3258001.

[14]. Sharma Amita, Pandey Kiran, Bhagoliwal Ajai (2013) Spot urine protein/creatinine ratio-A quick and accurate method for diagnosis of pre-eclampsia. Open Journal of Obstetrics and Gynecology, 2013, 3, 609-612 OJOG http://dx.doi.org/10.4236/ojog.2013.38109 Published Online October 2013 (http://www.scirp.org/journal/ojog/)

[15]. Thasneem Mohammed Arif, Jamila Hameed, S Haseena, Madhumitha Sekaran Ramya Ramadoss (2014) An interesting Case of Delayed Onset Postpartum Eclampsia, IJSS Case Reports \& Reviews | December 2014 | Vol 1 | Issue 7, http://www.ijsscr.com/sites/default/files/articles/IJSS-CR_1(7)_CR05.pdf

[16]. Takahiro Yamada, Takashi Yamada, Mamoru Morikawa, Masamitsu Takeda, Ryutaro Nishida, Rina Akaishi, Hisanori Minakami (2011) Isolated proteinuria as an initial sign of severe preeclampsia. Open Journal of Obstetrics and Gynecology, 2011, 1, 13-16 doi:10.4236/ojog.2011.12003 Published Online June 2011 (http://www.SciRP.org/journal/ojog/OJOG). Published Online June 2011 in SciRes. http://www.scirp.org/journal/OJOG

[17]. Uzan Jennifer, Carbonnel Marie, Piconne Olivier, Asmar Roland, and Jean-Marc Ayoubi (2011) Preeclampsia: pathophysiology, diagnosis, and management, Vasc Health Risk Manag. 2011; 7: 467-474.Published online 2011 doi: 10.2147/VHRM.S20181,PMCID: PMC3148420

[18]. WHO, 2005.http://www.who.int/whosis/mme_2005.pdf

[19]. World Health Organization 2011, WHO recommendations for Prevention and treatment of pre-eclampsia and $\begin{array}{lllllllllll}\text { eclampsia, } & \text { ISBN } & 978 & 92 & 4 & 154833 & 5 & \text { (NLM classification: } & \text { WQ } & \text { 215). http:// }\end{array}$ www.apps.who.int/iris/bitstream/10665/44703/1/9789241548335_eng.pdf.

[20]. World Health Organization, 2015, Trends in Maternal Mortality: 1990 to 2015 - World Health Organization www.apps.who.int/iris/bitstream/10665/194254/1/978924 1565141_eng.pdf

[21]. (www.elsevier.com/locate/preghy). 